\title{
Publication Ethics Policies for Journal of Advances in Internal Medicine (JAIM) \\ DOI Name \\ http://dx.doi.org/10.3126/jaim.v2i2.8784
}

\section{INTRODUCTION}

Journal of Advances in Internal Medicine (JAIM) is a biannual, peerreviewed, open-access, international medical journal [ISSN 2091-1432 (Print) and 2091-1440 (Online at www.aimjournal.org). Journal of Advances in Internal Medicine (JAIM) is a peer reviewed open access biomedical international journal and publishes the original research and critical reviews dealing with all disciplines of Internal Medicine. It is the official journal of the Society of Internal Medicine of Nepal (SIMON) and is published twice a year (January and July). Each issue of JAIM publishes Original Articles, Review Articles, Medical Images, Brief Reports, Editorials and Letters to the Editor. JAIM stands as a forum from which the researches conducted in various disciplines in medicine, the reviews done, novel and unique cases which we encounter during our professional career can be made available to our readers.

The publication of a manuscript comes from respected network of knowledge. It reflects the quality work of the authors and the institutions that support them. Peer-reviewed articles support and embody the scientific method. This leads to the importance of ethical responsibility that follows on to any author, editor, reviewer and owner of the journal. Based on a number of industry organizations, notably the Committee on Publication Ethics (COPE), the World Association of Medical Editors (WAME), the International Committee of Medical Journal Editors (ICMJE), Consolidated Standards Of Reporting Trials (Consort) and Elsevier Publication a comprehensive policy on publication ethics is summarized here, which addresses all the major areas JAIM considers important. Policies are given in order of manuscript supervisions.

\section{ETHICAL CONSIDERATIONS}

Ethics committee approval from respective health institution is obligatory for all manuscript submission. Following information should be presented. Manuscripts reporting data obtained from research conducted in human subjects must include a statement of assurance in the Methods section of the manuscript that

Informed consent was obtained from each patient and The study protocol conforms to the ethical guidelines of the 1975 Declaration of Helsinki as reflected in a priori approval by the institution's human research committee.

Ethics committee approval statement (IRC approval) is compulsory at the time of manuscript submission. JAIM does not have any policy for accepting/considering manuscripts reporting experiments using animals.

\section{PATIENT CONSENT}

Studies on patients or volunteers require ethics committee approval and informed consent, which should be documented in submitted manuscript. Patients' right must be respected and hence, identifying information, including patients? Images, names, initials, or hospital numbers, should not be included in videos, recordings, written descriptions, photographs, and pedigrees unless the information is essential for scientific purposes and you have obtained written informed consent for publication in print and electronic form from the patient (or parent, guardian or next of kin where applicable).

If such consent is made subject to any conditions, JAIM must be made aware of all such conditions. Written consents must be provided to JAIM on request. Even where consent has been given, identifying details should be omitted if they are not essential. If identifying characteristics are altered to protect anonymity, such as in genetic pedigrees, authors should provide assurance that alterations do not distort scientific meaning and editors should so note.

If such consent has not been obtained, personal details of patients included in any part of the paper and in any supplementary materials (including all illustrations and videos) must be removed before submission.

\section{AUTHORSHIP CRITERIA}

An "author" generally considered as someone who has made substantive intellectual contributions to a published study, and biomedical authorship continues to have important academic, social, and financial implications.

\section{Authors should meet following conditions}

Authorship credit should be based on

- Substantial contributions to conception and design, acquisition ofdata, or analysis and interpretation of data;

- Drafting the article or revising it critically for important intellectual content; and

- Final approval of the version to be published

When a large, multicentric group has conducted the work, the group should identify the individuals who accept direct responsibility for the manuscript. These individuals should fully meet the criteria for authorship defined below, and editors will ask these individuals to complete journalspecific author and conflict- of-interest disclosure forms. When submitting a manuscript authored by a group, the corresponding author should clearly indicate the preferred citation and identify all individual authors as well as the group name. To qualify for authorship, one must be available for each of the 3 categories of contributions listed below. To have made substantial contributions to the intellectual content of the paper as described above.

1. (At least 1 of the 3 below)

- Conception and design

- Acquisition of data

- Analysis and interpretation of data

2. (At least 1 of 2 below)

- Drafting of the manuscript

- Critical revision of the manuscript for Important intellectual content

3. (At least 1 below)

- Statistical analysis

- Obtaining funding

- Administrative, technical, or material support

- Supervision 
JAIM appeals those that don't meet the authorship-defined criteria, to be mentioned in Acknowledgement section of the manuscript. JAIM discourages "honorary" authorship and should also try to ensure that all those who qualify as authors are listed.

\section{CORRESPONDING AUTHOR}

The corresponding author should ensure that all appropriate coauthors and no inappropriate coauthors are included on the paper, and that all coauthors have seen and approved the final version of the paper and have agreed to its submission for publication.

\section{DISCLOSURE AND CONFLICTS OF INTEREST}

Submission of manuscript also entails author/s disclose all their competing interests, including specific financial interests and relationships and affiliations relevant to the subject matter or materials discussed in the manuscript. These are also to be disclosed in the Acknowledgment section of the manuscript. All authors should disclose in their manuscript any financial or other substantive conflict of interest that might be construed to influence the results or interpretation of their manuscript. All sources of financial support for the project should be disclosed.

Examples of potential conflicts of interest, which should be disclosed, include employment, consultancy, stock ownership, honoraria, paid expert testimony, patent applications/registrations, and grants or other funding. Potential conflicts of interest should be disclosed the earliest stage possible.

\section{DUTIES OF AUTHORS}

\section{Reporting standards}

An accurate account of the implemented work and results should be presented, along with an objective discussion of its significance. Underlying data should be represented accurately in the paper. A paper should contain sufficient detail and references to permit others to replicate the work. Fraudulent or knowingly inaccurate statements constitute unethical behavior and are unacceptable. Review and professional publication articles should also be accurate and objective, and editorial 'opinion' works should be clearly identified as such.

\section{Data access and retention}

Authors may be asked to provide the raw data in connection with a paper for editorial review, and should be prepared to provide public access to such data, if practicable, and should in any event be prepared to retain such data for a reasonable time after publication.

\section{Originality and plagiarism}

The authors should ensure that they have written entirely original works, and if the authors have used the work and/or words of others, that this has been appropriately cited or quoted. Plagiarism in all its forms constitutes unethical publishing behaviour and is unacceptable. For more information, please refer to Section on Plagiarism of this document.

\section{Multiple, redundant or concurrent publication}

An author should not in general publish manuscripts describing essentially the same research in more than one journal or primary publication. Submitting the same manuscript to more than one journal concurrently constitutes unethical publishing behaviour and is unacceptable.

\section{Acknowledgement of sources}

Proper acknowledgment of the work of others must always be given. Authors should cite publications that have been influential in determining the nature of the reported work. Information obtained privately, as in conversation, correspondence, or discussion with third parties, must not be used or reported without explicit, written permission from the source. Information obtained in the course of confidential services, such as refereeing manuscripts or grant applications, must not be used without the explicit written permission of the author of the work involved in these services.

\section{Fundamental errors in published works}

When an author discovers a significant error or inaccuracy in his/her own published work, it is the author's obligation to promptly notify the journal editor or publisher and cooperate with the editor to retract or correct the paper. If the editor or the publisher learns from a third party that a published work contains a significant error, it is the obligation of the author to promptly retract or correct the paper or provide evidence to the editor of the correctness of the original paper.

\section{COPYRIGHT TRANSFER}

Submission of an original manuscript to the Journal will be taken to mean that it represents original work not previously published, that it is not being considered elsewhere for publication, and that the author is willing to assign copyright to the journal as per a contract that will be sent to the author just prior to publication. If accepted for publication, it will be published online and in print and it will not be published elsewhere in the same form, for commercial purposes, in any language, without the consent of the publisher.

Publication of scholarly research is meant to disseminate knowledge and, in a not-for-profit regime, benefits neither publisher nor author financially. Authors who publish in the Journal of Advances in Internal Medi- cine agree to transfer their rights to JAIM. JAIM will then release their articles under the Creative Commons Attribution Unported (CC BY 3.0) International License. This license allows anyone to copy and distribute the article for non-commercial purposes provided that appropriate attribution is given. For details of the rights an author grants users of their work, please see the license summary at following web page - http:// creativecommons.org/licenses/by/3.0/ 
What rights do I retain as a journal author?

- The right to make copies (print or electronic) of the journal article for your own personal use, including for your own classroom teaching use

- The right to make copies and distribute copies of the journal article (including via e-mail) to research colleagues, for personal use by such colleagues for scholarly purposes

- The right to post a preprinted version of the journal article on Internet websites including electronic preprinted servers, and to retain indefinitely such version on such servers or sites for scholarly purposes

- The right to post a revised personal version of the text of the final journal article (to reflect changes made in the peer review process) on your personal or institutional website or server for scholarly purposes, incorporating the complete citation and with a link to the Digital Object Identifier (DOI) of the article

- The right to present the journal article at a meeting or conference and to distribute copies of such paper or article to the delegates attending the meeting

- $\quad$ The right to use the journal article or any part thereof in a printed compilation of your works, such as collected writings or lecture notes (subsequent to publication of the article in the journal);
Following rights will be held by JAIM under Creative Commons Attribution-Noncommercial-No Derivative Works 3.0 International License.

- The right to prepare other derivative works, to extend the journal article into book-length form, or to otherwise re-use portions or excerpts in other works, with full acknowledgement of its original publication in the journal.

\section{Why does JAIM request transfer of copyright,} before releasing into Creative Common License?

The research community needs certainty with respect to the validity of scientific papers, which is normally obtained through the editing and peer review processes. The scientific record must be clear and unambiguous. JAIM believes that, by obtaining copyright transfer, it will always be clear to researchers that when they access an JAIM site to review a paper, they are reading a final version of the paper which has been edited, peer-reviewed and accepted for publication in this appropriate journal.

\section{PLAGIARISM}

Plagiarism is the use of others' published and unpublished ideas or words (or other intellectual property) without attribution or permission, and presenting them as new and original rather than derived from an existing source. This applies whether the ideas or words are taken from abstracts, research grant applications, Institutional Review Board applications, or unpublished or published manuscripts in any publication format (print or electronic).

\section{JAIM defines plagiarism as}

Whenever an author uses another person's exact words, they must be placed in quotation marks and a citation must be given. The reader of an article in JAIM must know which words are the author's and which belong to someone else. Even documents in the public domain, such as government documents, must be attributed to their source.

\section{Self-plagiarism}

The author's copying of her or his own previously published material: duplicate publication or "self-plagiarism." If an author has published an article in Journal A, she or he may not send the same article with a few minor adjustments to Journal B. Nor may she or he take verbatim portions of the first article without quotation marks for use in a second article. Each publication should contain fresh writing, even if there is nothing new to report on the topic.

\section{Inadequate acknowledgement of data or ideas}

Most writers rely on the ideas and data of others, but doing so without naming the source is a form of plagiarism.

\section{Copyright infringement}

Occurs when an author copies (with or without attribution) significant portions of a published work, including tables and figures, without having obtained the permission of the person or publisher holding the copyright. When this plagiarized "writing" is published, the new publisher is guilty of violating the copyright held by the original publisher.

\section{Excessive or poor rephrasing}

An author may believe that juggling the words of a copied-and-pasted sentence from another article is adequate. It is not. Also, it is not acceptable for an author's work to be made up largely of paraphrased sentences from other published material. And the ordering of information presented in an article must be original and not too closely follow another published work.

\section{POLICY FOR MISCONDUCT}

JAIM policy on plagiarism is shaped by two desires: to inform authors of acceptable writing practices and to set a very high standard for the publication of peer-reviewed articles.

When plagiarism is detected, by either peer reviewers or staff editors, before or after acceptance, during editing, or at any time before publication, JAIM staff will alert the author, asking her or him to rewrite or quote exactly and to cite the original source.If the plagiarism is extensive-that is, if at least $25 \%$ of the original submission is plagiarized-the article may be rejected and the author's employer notified of the violation. If plagiarism is detected after publication, the editors will notify readers of the infraction through an editor's note in the journal, and the author's employer may be notified of the breach. 


\section{DUTIES OF AUTHORS}

\section{TYPES OF ARTICLES}

In each issue, we publish articles under certain types/ sections. The types of articles we publish are as follows:

$\begin{array}{ll}\text { - } & \text { Editorials } \\ \text { - } & \text { Original Articles } \\ \text { - } & \text { Case Reports } \\ \text { - } & \text { Review articles } \\ \text { - } & \text { Medical Images } \\ & \text { Letters to the Editor }\end{array}$

Beside the regular types of articles we also sometimes publish articles under categories like Invited Articles (See below for details of each type), Proceedings/ Declaration of Conferences/Congress, Updates, Supplements, etc. The types are determined by the title, aim(s) and objective(s), and most importantly the content of the manuscript. We also require that the author clearly specifies the type of article $s / h e$ is submitting. However, the final decision under which category the article is published rests on the decision of the editorial board. In such case, the author will be duly informed regarding the decision. The author will have the right to withdraw the article if s/he chooses, but must do so within the specified time.

\section{Number of Authors}

Editors should not arbitrarily limit the number of authors. There are legitimate reasons for multiple authors in some kinds of research, such as multi-center, randomized controlled trials. In these situations, a subset of authors may be listed with the title, with the notation that they have prepared the manuscript on behalf of all contributors, who are then listed in an appendix to the published article. Alternatively, a "corporate" author (e.g., a "Group" name) representing all authors in a named study may be listed, as long as one investigator takes responsibility for the work as a whole. In either case, all individuals listed as authors should meet criteria for authorship whether or not they are listed explicitly on the byline. If editors believe the number of authors is unusually large, relative to the scope and complexity of the work, they can ask for a detailed description of each author's contributions to the work. If some do not meet criteria for authorship, editors can require that their names be removed as a condition of publication.

\section{Order of Authorship}

The authors themselves should decide the order in which authors are listed in an article. No one else knows as well as they do their respective contributions and the agreements they have made among themselves. Many different criteria are used to decide order of authorship. Among these are relative contributions to the work and, in situations where all authors have contributed equally, alphabetical or random order. Readers cannot know, and should not assume, the meaning of order of authorship unless the approach to assigning order has been described by the authors. Authors may want to include with their manuscript a description of how order was decided. If so, editors should welcome this information and publish it with the manuscript.

\section{Authorship Disputes}

Disputes about authorship are best settled at the local level, before journals review the manuscript. However, at their discretion editors may become involved in resolving authorship disputes. Changes in authorship at any stage of manuscript review, revision, or acceptance should be accompanied by a written request and explanation from all of the original authors.

\section{Contributors Listed in Acknowledgments}

All contributors who do not meet the criteria for authorship should be listed in an acknowledgments section. Examples of those who might be acknowledged include a person who provided purely technical help, writing assistance, or a department chairperson who provided only general support. Editors should ask corresponding authors to declare whether they had assistance with study design, data collection, data analysis, or manuscript preparation. If such assistance was available, the authors should disclose the identity of the individuals who provided this assistance and the entity that supported it in the published article. Financial and material support should also be acknowledged.

Groups of persons who have contributed materially to the paper but whose contributions do not justify authorship may be listed under such headings as "clinical investigators" or "participating investigators," and their function or contribution should be described-for example, "served as scientific advisors," "critically reviewed the study proposal," "collected data," or "provided and cared for study patients." Because readers may infer their endorsement of the data and conclusions, these persons must give written permission to be acknowledged.

\section{Manuscript processing}

Manuscripts are processed as per standard procedure mentioned in JAIM policy for manuscript processing. In case of any confusion, author can contact JAIM at editor@aimjournal.org or info@ aimjournal.org

Manuscript submission

Authors may submit manuscripts via email in the following address: editor@aimjournal.org . All manuscripts must be addressed to the Chief Editor, JAIM. 
Paper Presentation and Format

JAIM has following outlines for paper presentation and formats.

1. Use double spacing throughout

2. Pages should have margins at least $25 \mathrm{~mm}$ and be numbered

3. Maintain the sequence title page, abstract, key words, text, acknowledgements, references and legends.

4. Text should be presented as per the nature of paper

5. The Cover page should carry the title, a short running title, total words count on abstract, total word count of manuscript, information of any disclaimers or funding bodies and the corresponding author's full names, qualifications, affiliations, departments, email and addresses of institute affiliated (street, city, country).

6. Authorship page should carry in sequence information on primary author, corresponding author, and other authors, with authors' full names, highest academic qualifications, affiliations, departments, email and addresses of institute affiliated (street, city, country). Also mention, authorship contribution of each author and their signatures.

7. Declaration page must be scanned and sent with signature of only one author - corresponding author or primary author.

8. Include permission to reproduce previously published material or to use illustrations that may identify participants

Use of Language

1. Uniformity in Language is required, with preference to American English

2. There should be no abbreviation in Abstract

3. Abbreviation spelt out in full for the first time

4. Avoid repetition of same words and waste words

5. Do not use ' $\&$ ' and '@' in the text

6. Running title provided should be not more than 50 characters

7. Format the manuscript in a single column

8. Do not use any special typeface for emphasis

\section{Use of Numbers}

1. Numbers less than 10 should be written in words.

2. Numbers 10 or more should be written in numbers.

3. Words not numbers begin a sentence.

4. Be consistent in lists of numbers.

5. Numbers less than 1 begin with a zero.

6. Do not use a space between a number and its percent sign.

7. Use one space between a number and its unit.

8. Report percentages to only one decimal place if the sample size is larger than 100

9. Do not use decimal places if the sample size is less than 100 .

10. Do not use percentages if the sample size is less than 20.

11. Do not imply greater precision than your measurement instrument.

12. For ranges use "to" but not "-" to avoid confusion with a minus sign and use the same number of decimal places as the summary statistic.

13. Rules for data numbers do not apply to citations to the literature

14. Us the metric system throughout; use of appropriate SI Units is encouraged. If using other, more commonly used units, give the SI equivalent in parenthesis.

\section{USE OF TABLES, FIGURES AND IMAGES}

1. Tables, Figure and Images number in Arabic letters (no Romans)

2. Title/legends provided in no more than 40 words

3. For borrowed materials - credit note must be provided in the figure/ table/image itself.

4. Keep the table/figures simple and uncluttered as possible

5. Standard abbreviation of units of measurement should be added in parentheses

Use of Tables

Rule of thumb: Use tables to present data that is detailed and that is important

6. Avoid tables created with the tab key, pictures and embedded objects

7. Fancy borders, shading, 3d effects, multiple grids are both distracting and unnecessary

8. Prefer grey shades of tables and figures

9. Scientific table have few horizontal lines and no vertical lines. Usually only three horizontal lines (above and below the column headings, below the table)

10. Tables should be formatted so that they have to be read horizontally (left to right) - the natural reading style

Use of Figures

Rule of thumb: Use figures to - Show trends in data (as graphs)

11. Do not use Pie charts, 3d bar diagrams, as Figures

12. Figures should be simple to interpret, uncluttered, and free of extra lines, text, dimensions and other gimmicks.

13. Prefer common data-presentation formats in figures: Column charts/bar charts; Line charts; Scatter plots

Use of Images/photographs

14. Do not create math equations or tables as pictures

15. For Images and photographs, use TIFF or a high resolution JPEG.

16. Figures necessitate good quality - $300 \mathrm{dpi}$ with minimum resolution of $800 \times 600$ pixel

\section{Relating to tables and figures in text}

17. Refer to all the tables/figures in the text

18. Point out the relevant part(s) of a table/figure when referring to it

19. Do not restate all the information from tables/figures in the text of the paper

20. Tables/figures should not be used to highlight what has already been said in the paper

Permissions

Written permission to reproduce borrowed material (illustrations, tables and photographs) must be obtained. Authors must ensure that appropriate permission has been obtained for the publication of identifiable clinical photographs. Borrowed and previously published material should be acknowledged in the captions in this style: 'Reproduced by kind permission of . . . (publishers) ... from ... (reference).' It is the responsibility of the author to obtain all such permissions from the original publishers and authors, and to submit them with the manuscript. 


\section{Drug names}

Generic drug names should be used.

\section{References}

Authors are instructed to follow Vancouver system for citing scientific literature. Authors can get a comprehensive explanation of the system

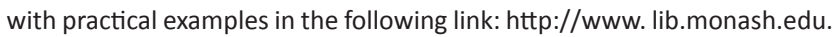
au/tutorials/citing/vancouver.html. or JAIM website. Authors must also note that JAIM follows following variation in Vancouver style.

- $\quad$ Superscripts must be used rather than brackets.

- Numbers (citations) should be inserted before colons and semicolons.(to the left)

- Numbers (citations) should be inserted after comas and full stops. (to the right)

- It is important that the punctuation and form is consistently applied to the whole document.

- Maximum number of references

$\begin{array}{ll}\text { Original Article - } & 60 \\ \text { Review Article - } & 150 \\ \text { Case Note - } & 25 \\ \text { Editorial - } & 20\end{array}$

- List first three authors followed by et al. for all references

\section{Abbreviations}

These are commonly used abbreviations to write in reference list

\begin{tabular}{|c|c|}
\hline c. = circa (about, approximately) & ed. = edition \\
\hline fig; figs = figure(s) & p. $=$ page $(s)$ \\
\hline pt. pts. = part(s) & Suppl. = Supplement \\
\hline ch. = Chapter & et al. = and others \\
\hline ill ills = illustrator(s) & para paras = paragraph(s) \\
\hline
\end{tabular}

For more information refer to JAIM Reference/Citation section

\section{Guidelines on individual article types}

Editorial

This is written in each issue by the editor or members of editorial board and is not open for external authors unless invited.

\section{Original Articles}

We publish all types of research articles, i.e. descriptive, analytical, and experimental. However, we believe that some descriptive studies fall under audit section more than as an original research article. Such articles which do not contribute substantially to existing knowledge or to new concepts, will be placed under AUDIT section of the journal.

Original Articles should have following headings in its manuscript:

$\begin{array}{ll}\text { - } & \text { Title } \\ \text { - } & \text { Abstract and Keywords } \\ \text { - } & \text { Introduction } \\ \text { - } & \text { Rethods } \\ \text { - } & \text { Discults } \\ \text { - } & \text { Conclusion } \\ \text { - } & \text { Acknowledgement } \\ \text { - } & \text { References }\end{array}$

\section{Orginal Article}

Title

- Complete title of the article

- Provide also Running title - not more than 50 characters

- Be short, accurate, and unambiguous giving your paper a distinct personality

- Begin with the subject of the study

- Avoid excessive adjectives and noun strings

\section{Abstract}

The abstract should contain the essence of the whole paper and should stand-alone. Be clear and concise and avoid unnecessary detail.

- Word limit - 250 words

- No abbreviation to be used in abstract

- Structured abstract - into following sub groups

- Background and Aims

- Methods

(study type/design, sample number, time and place)

- $\quad$ Results

(include most important results only)

- Conclusion

Keywords

- Keywords - 3-5 words, seperated by semicolons

- Use Keywords from MeSH index website http://www.ncbi.nlm.nih.gov/mesh

Body of Original Article (excluding references)

- maximum of 3000 words

- maximum of 5 tables/figures

Introduction

- Introductions should be short and arresting and tell the reader

why you undertook the study

- Divide the Introduction into three parts

a. The first paragraph should be a very short summary of the exiting knowledge of your research area.

b. This should lead directly into the second paragraph that summarizes what other people have done in this field, what limitations have been encountered with work to date, and what questions still need to be answered.

c. This, in turn, will lead to the last paragraph, which should clearly state what you did and why.

- Do not write conclusion in this section

Methods

Basically, it should include three questions: How was the study designed? How was the study carried out? and How was the data analysed?

Mention following, in order of their appearance, and writing in past tense or passive verb

I. Study type and study design

II. Place and duration of study

III. Sample size and Sampling method

IV. Methods of data collection

V. Ethical Approval and Patient consent

VI. Inclusion and exclusion criteria 
VII. Protocols followed (if any)

VIII. Statistical analysis and software used

You should give precise details of the questionnaires you used and how they were developed, validated, and tested for repeatability. If JAIM questions, you should be able to provide the questionnaire.

When the sample size is smaller than 40 , the results are rarely believable, the summary estimates lack of precision, standard statistical methods may be inappropriate, and the generalizability of the results will be questionable. It is always important to include details of your sample size calculations.

For comparison. You must also describe the methods of randomization, allocation concealment and blinding of the research staff and the participants to study group allocation. You must also describe any procedures that you used to maximize or measure compliance with the interventions. If a drug is being tested, then the generic name, the manufacturer, the doses used and any other information should be included.

Results

You should use an interesting sequence of text, tables, and figures to answer the study questions and to tell the story without diversions. Remember that results and data are not the same thing. You do not need to repeat numbers in the text that are already presented in a table or a figure.

- It is essential that you are consistent in the use of units in your reporting so that readers can make valid comparisons between and within groups. JAIM require you to use Système Internationale $(\mathrm{SI})$ units

- Clearly present relevant data, and avoid data redundancy

- Only significant results must be shown under this heading

- Use a mixture of text, tables, and figures

- Avoid using percentages unless the group have more than 100 subjects

- When condensing results give the number of subjects, the range of results, the central tendency (mean \pm SD), and the spread (confidence interval for the mean)

- If you have done an analysis of variance give the estimates with their degrees of freedom and $p$ values

- Prepare tables and figures according to the instructions mentioned above

- Tables and illustrations/graphs/ charts should not represent the same results. Use the space below the legend to show some important findings.

- Write all your result text under one section referring to appropriate legends.

\section{Template for Result, in order of their appearance}

I. Describe study sample. Who did you study?

II. Univariate analyses - How many participants had what?

III. Bivariate analyses - What is the relation between the outcome and explanatory variables?

IV. Multivariate analyses - What is the result when the confounders and effect modifiers have been taken into account?

\section{Discussion}

- Discuss major findings. It should not merely be a repetition of results section. Only duplicating data from results section into this heading is NOT allowed
- Avoid unnecessary explanation of someone else work unless it is very relevant to the study. Other studies should be quoted in relation to the findings of the present study.

- Provide and discuss with the literatures

to support the study

- Mention about

$$
\begin{aligned}
& \text { a. Limitations of your study (if any) } \\
& \text { b. Confounding factors } \\
& \text { c. Possible implications which are not } \\
& \text { mentioned in the abstract }
\end{aligned}
$$

An otherwise very good manuscript but with poor discussion may be rejected for the same reason

Conclusion

Template for Conclusion, in order of their appearance

I. What did this study show? Address the aims stated in the Introduction

II. Strengths and weaknesses of methods

III. Discuss how the results support the current literature or refute current knowledge

IV. Future directions "So what?" and "where next?" Impact on current thinking or practice

Also make note of the following

V. Give recommendation from your study

\section{Acknowledgement}

Acknowledge any person or institute who have helped the study Make acknowledgement short and do not add praise or literature in this section

References

Abide by JAIM guideline - Vancouver citation method.

Maximum number of references

$\begin{array}{ll}\text { Original Article - } & 60 \\ \text { Medical Image - } & 3 \\ \text { Review Article - } & 150 \\ \text { Case Report - } & 25 \\ \text { Editorial - } & 20\end{array}$

Legends

Table e.g. (Table 1) and Figure e.g. (Figure 3)

Put tables, charts, and figures at the end of the paper, after references

\section{Medical Image}

Medical image presents a striking clinical image that is meant to challenge and inform readers. The answer should be no more than 350 words. The section is intended to illustrate and teach important medical points. The answer should discuss the image findings and the diagnosis in no more than one double-spaced typed page.

The diagnosis and discussion should make an important medical The diagnosis and discussion should make an important medical teaching point and include up to three pertinent references. Information regarding the specific patient in terms of follow-up and response to therapy should be given as appropriate. No more than three authors are allowed on each submission. 


\section{Case Report}

Title

- Complete title of the article

- Provide also Running title

- Be short, accurate, and unambiguous giving

your paper a distinct outlook

- Begin with the subject of the study

- Avoid excessive adjectives and noun strings

Abstracts

The abstract should contain the essence of the whole paper and should stand-alone. Be clear and concise and avoid unnecessary detail.

- Word limit - 150 words

- No abbreviation to be used in abstract

- Non Structured abstract

- Provide - Age and Gender of the Case

Keywords

- Keywords - 3-5 words, separated by semicolons

- Use Keywords from MeSH index -

website http://www.ncbi.nlm.nih.gov/mesh

Body of Case Report (excluding references)

- maximum of 1500 words

- maximum of 3 tables/figures

Introduction

- Introduce the case in short and highlight the importance of presenting it as a case report in the journal

Case Report

- Reason for reporting this case

- Avoid waste words

- The report should detail: what happened to the patient, the time course of events, why the particular management was chosen

\section{Discussion}

Provide and discuss latest literatures about your case report Mention about limitation of the reporting, if any Valid written expressed consent from patient/s must be taken prior to involving any person in case note manuscript. The identity of the patient must not be revealed by text or figures. If the figure/picture tends to reveal the identity of the individual, it is the responsibility of the author to have explained so to the patient before submitting the manuscript

Acknowledgement, References and Legends to be used as mentioned in Original Article. Not more than 20 references in Case Report.

\section{Review Article}

Review article must incorporate various aspects of the topic chosen, and should also incorporate latest researches and findings. It should not merely be a collection of quotes from textbooks or very old articles of journals that does not contribute anything new to the scientific literature base already available.

Ideal Contents of a review:

$\begin{array}{ll}\text { - } & \text { What is the problem? } \\ \text { - } & \text { Historical background } \\ \text { - } & \text { Basic science } \\ \text { - } & \text { Hethodology } \\ \text { - } & \text { Discussion } \\ \text { - } & \text { Conclusions } \\ \text { - } & \text { Recommendations }\end{array}$

The ideal review should be topical, up to date, balanced, accurate, authoritative, quotable, provocative and a good read.

Body of Review Article (excluding references)

- maximum of 3000 words

- maximum of 5 tables/figures

\section{Specially invited articles}

Articles which are specially invited in JAIM from the editorial board may fall among any one of the types mentioned above and should follow the guidelines as above just the same.

\section{Letter to the Editor}

Letter to the Editor will be accepted or edited and published at the Editor's discretion. The author must give a full reference of the article published in JAIM while writing the letter to which he is referring. While writing be succinct (approximately 325 words) and address one or two major subjects regarding the article. Letters that, in the Editor's view, require a response from the authors of the article will be held pending notification of the authors, who will have fifteen days to respond. On receipt of an author's response, the letter and the author response will be published in the journal and will also be posted in the web. If we do not receive an author response within fifteen business days, the letter will be published with a note stating, "The author has been invited to respond and has not done so."

General instructions to authors

- The decision of the editor will be final for modification or rejection. However, the author may withdraw his/her manuscript prior to publication when given a chance by the editor (e.g. after modification).

- If the authorship of a paper is changed in any way after it has been reviewed, the Editor will require a letter, signed by all authors named on the original or on the revised submission, explicitly agreeing to the change.

- Additional prints/ republication/translation:

- As JAIM is an Open Access Journal and we post all the articles published in the web in PDF format, the author may print 
additional copies. However, for doing so the author has an obligation to inform JAIM. This will also help us in tracking reprinted articles. However, if the quantity of reprints required is more than 50 or in a commercial basis, prior written permission is required by the author from the Chief Editor of JAIM.

- For republication of the article in another journal, the author must seek prior permission from JAIM, clearly stating the purpose and request for permission to print again.

- For translation of the article and publication in another language (in another journal), the author must seek prior permission from JAIM along with the purpose and request for permission to print again. Both the above mentioned points require to be compliant with ICMJE guidelines for reprints and translation.

- The submitted manuscript should actually represent the scientific work done and the data should not be manipulated for whatsoever purpose.

- Any irregularities, misinformation, or manipulation of the data tending to skew the conclusion towards the side that does not represent the actual finding, if found, can result in the manuscript to be rejected or retracted (if already published). JAIM may proceed with legal actions if needed in appropriate cases.

- If authors of a published article subsequently become aware of a significant error in it, they should send a notifying letter to the editor of JAIM as soon as possible. If the mistake is judged significant enough to warrant a published correction, the correction will be made as an "erratum" if the fault is JAIM's; "correction" if the fault is the author's.

Color online

We are usually able to substitute color versions of illustrations in the online journal at no cost. Authors wishing to take advantage of this facility are asked to submit a high quality color image file for producing it electronically during their initial submission.

JAIM reserves the right whether or not to accept color work that is not submitted in the format described above.

\section{Supplementary online material}

Authors wishing to include additional material supporting a paper for which there is no space in the printed journal, may wish to have this made available online with the paper on the JAIM website. These supplementary materials must be submitted with the original manuscript and will be shown to the reviewers and the editors.

This allows papers to have greater depth, online enhancements, such as video clips and additional data sets, making them more useful to fellow specialists in the field who require detail, without distracting more general readers.

Authors should ensure that supplementary information is supplied in its FINAL format because it is not subedited and will appear online exactly as submitted. It cannot be altered, nor can new supplementary information be added, after the paper has been accepted for publication.

\section{Supplement proposals may be made at the request of: chief editor}

The journal editor, an editorial board member or a learned society may wish to organize a meeting, sponsorship may be sought and the proceedings published as a supplement.

The journal editor, editorial board member or learned society may wish to commission a supplement on a particular theme or topic. Again, sponsorship may be sought.

JAIM itself may have proposals for supplements where sponsorship may be necessary.

A sponsoring organization, often a pharmaceutical company or a charitable foundation, that wishes to arrange a meeting, the proceedings of which will be published as a supplement.

In all cases, it is vital that the journal's integrity, independence and academic reputation is not compromised in any way.

JAIM is willing to consider publishing supplements to regular issues. 


\section{CHECKLIST}

Please make sure that you have addressed all the points mentioned in the checklist

\author{
$\square$ Cover letter \\ - Title of the manuscript \\ - Short - Running Title \\ - Abstract \\ - Total Words Count on Abstract \\ - Total Words Count on Manuscript (excluding the reference section) \\ - Information of any disclaimers or funding bodies \\ - Corresponding Author - \\ Full names Email Address \\ Qualification Affiliated Department \\ Addresses of institute affiliated (street, city, country)
}

\section{Authorship Statement Form}

Authorship page should carry in sequence information on primary author, corresponding author, and other authors, with authors' full names, qualifications, affiliations, departments, email and addresses of institute affiliated (street, city, country). Also mention, authorship contribution of each author and their signatures.

\section{$\square \quad$ JAIM Declaration Form (Completely filled)}

Declaration page must be scanned and sent with signature of either Corresponding Author, or Primary Author

\section{$\square \quad$ Manuscript file}

- Title of the manuscript

- Short - Running Title

- Abstract

- Manuscript Text

- References

- Tables/Chart (not in image/picture format)

- Do Not embed figure/Image on this file

- Do Not include any author information

\section{Supporting File/s}

Include individual Image/Picture files (jpeg, tiff) - with minimum 300dpi pixel count and $800 \times 600$ size.

$\square \quad$ Ethical Approval Letter

MUST INCLUDE - Ethical Approval Letter from respective IRC- (scanned)

\section{THE DOI SYSTEM}

A digital object identifier (DOI) is a character string (a "digital identifier") used to uniquely identify an object such as an electronic document. Metadata about the object is stored in association with the DOI name and this metadata may include a location, such as a URL, where the object can be found. The DOI for a document is permanent, whereas its location and other metadata may change. Referring to an online document by its DOI provides more stable linking than simply referring to it by its $U R L$, because if its URL changes, the publisher need only update the metadata for the DOI to link to the new URL. Resolve any JAIM paper (DOI Name) via the website - http://www.doi.org/

\section{Citation and Referencing}

Journal of Advances in Internal Medicine (JAIM) uses modified Vancouver Style in all it's assessment tasks.

\section{Using Vancouver Style}

Vancouver Style uses in-text citations and a Reference List at the end of your document. A citation is an acknowledgement in your text of references that support your work. It is in the form of a number that correlates with a source in your reference list.

\section{Citations}

In the Vancouver Style, Arabic numbers in superscript identifies citations within the text of the essay/paper. This applies to references in text, tables and figures.

- Citations within the text of your paper are identified with a superscript numbers.

example - Giri ${ }^{1}$ has argued that...

- References are numbered consecutively in the order they are first used in the text. The full citations will be included in the Reference List at the end of your document, with matching numbers identifying each reference.

-When multiple references are cited together, use a hyphen to indicate a series of inclusive numbers. Use commas to indicate a series of non-inclusive numbers. A citation with these references $(4,5,6,7,14,19)$ is abbreviated to $(4-7,14,19)$. example - Several clinical trials ${ }^{4-6,9}$ show...

- The original number used for a reference is reused each time the reference is cited.

example - "...the theory was first put forward by Giri" in 1999 , but there was disagreement ${ }^{3,5,8}$ over its importance."

- The placement of citation numbers within text should be carefully considered e.g. a particular reference may be relevant to only part of a sentence. As a general rule, reference numbers should be placed outside full stops and commas and inside colons and semicolons; preferred $^{11}$

example - ...a new definition. ${ }^{13, \text { p111-2 }}$...this option is

- Citing a specific page:

example - Patients showed no signs of diabetes. ${ }^{1(p .23), 9}$ example - Kailash ${ }^{(p .3,6)}$ reported no sign of.... (more than one page cited)

\section{Reference List}

- A reference list contains details only of those works cited in the text of the document. (eg. book, journal article, pamphlet, internet site, cassette tape or film). These details must include sufficient detail so that others may locate and consult your references.

- A reference list should appear at the end of your article/report with the entries listed numerically and in the same order that they have been cited in the text.

- Sources cited from the Internet should be in your reference list 


\section{Journal Articles}

Standard Format for Journal Articles

Author's surname Initials, Author's surname Initials. Title of article. Title of Journal [abbreviated] Year of publication Month date;Volume Number(Issue number):page numbers.

Journal articles can be accessed in three different ways:

(1) from the print (paper) copy;

(2) from the journal's website; or

(3) from an online article database like Medline.

You will cite the article differently depending on how you accessed it. Vancouver Style of referenceing does not use the full journal name. It uses commonly-used abbreviation journal titles. Abbreviation can be found from:

PubMed Journals Database website:

http://www.ncbi.nlm.nih.gov/entrez/query. fcgi?db=journals

- Only first words of article title and words that normally begin with a capital letter are capitalized.

- First 3 authors are listed; thereafter add an et al. after the third author.

- If the journal has continuous page numbering, you may omit month/issue number.

- Remember that, reference to a journal article will need.

1. The year when the journal was published.

2. The volume number.

3. Perhaps a part number - Volumes may be published in several parts. Generally in the Vancouver style you can omit the part number unless each part of the journal starts numbering pages at page 1 or the reference is from a supplement.

4. The page numbers of the article itself. If the article is on pages 11-15, in the Vancouver style you can abbreviate this to 11-5.

\section{Examples}

Journal Article in Print

1. Haas AN, de Castro GD, Moreno T, et al. Azithromycin as a adjunctive treatment of aggressive periodontitis: 12-months randomized clinical trial. J Clin Periodontol 2008 Aug;35(8):696704.

Journal Article from a Website

2. Tasdemir T, Yesilyurt C, Ceyhanli KT, et al. Evaluation of apical filling after root canal filling by 2 different techniques. J Can Dent Assoc [Internet]. 2009 Apr [cited 2009 Jun 14];75(3):[about 5pp.]. Available from: http://www.cda-adc.ca/ jcda/vol-75/issue-3/201.html

Journal Article from an Online Database

3. Erasmus S, Luiters S, Brijlal P. Oral hygiene and dental student's knowledge, attitude and behaviour in managing HIV/ AIDS patients. Int J Dent Hyg [Internet]. 2005 Nov [cited 2009 Jun 16];3(4):213-7. Available from Medline: http://cclsw2. vcc.ca:2048/login?url=http://search.ebscohost.com/login. aspx?direct $=$ true $\& d b=c m e d m \& A N=16451310 \&$ site $=$ ehost-live

4. Monajem S. Integration of oral health into primary health care: the role of dental hygienists and the WHO stewardship. Int J Dent Hyg [Internet]. 2006 Feb [cited 2009 Jun 21];4(1):47-52. Available from CINAHL with Full Text: http://tinyurl.com/kudbxw
Creating Small URLs If the URL of an article is long, go to: www. tinyurl.com. Create a working link to a website that is shorter.

Journal Article in Press

5. O'Leary C. Vitamin C does little to prevent winter cold. The West Australian Forthcoming 2005 June 29.

Can include date, volume and issue number if provide; Add manually - "Forthcoming" and year and date if provided. "Forthcoming" is used instead of "in press"

Journal Articles with Corporate authors

6. The Royal Marsden Hospital Bone-Marrow Transplantation Team. Failure of syngeneic bone-marrow graft without preconditioning in post-hepatitis marrow aplasia. Lancet 1977;2:242-4.

Journal Articles with no author given

7. Anonymous. Coffee drinking and cancer of the pancreas (editorial). Br Med J 1981;283:628

\section{Other examples of Journals with parts and/or supplements}

Cochrane Library Review

Entered cited date manually and

change the medium to "Internet"

8. Shaw KA, O'Rourke P, Del Mar C, et al. Psychological interventions for overweight or obesity. Cochrane Database of Systematic Reviews [Internet] 2005 [cited 2010 Apr 10]. Available from: http://www.mrw.interscience.wiley.com/ cochrane / clsysrev/articles/CD003818/frame.html

Electronic article - with DOI number

Add DOI number manually

9. Fletcher D, Wagstaff CRD. Organisational psychology in elite sport: its emergence, application and future. Psychol Sport Exerc. 2009;10(4):427-34. doi:10.1016/j.psychsport.2009.03.009.

\section{Other Examples}

Journal with supplement Environ Health Perspect 1994;102(Suppl 1):275-82. Issue with Supplement Semin Oncol 1996:23(Suppl. 2):89-97.

Volume with part

Ann Clin Biochem 1995;32(pt. 3):303-6.

Issue with part

N Z Med J 1994;107(986 pt. 1):337-8.

Issues with no volume

Clin Orthop 1995;(320):110-4.

No Issues or volume

Curr Opin Gen Surg 1993:325-33. 


\section{Books}

\section{Standard Format for Books}

Author Surname Initials. Title: subtitle. Edition (if not the first). Place of publication: Publisher; Year.

Reference to a book will need.

1. The edition number, Arabic number followed by nonsuperscript denotations eg. 11th ed.

2. Begin a reference to a contribution with information about the contribution, followed by the word "In:" and information about the book itself.

3. Begin a reference to a part of a book with the book itself, then follow it with information about the part.

\section{Examples}

Book with One Author or Editor

10. Mason J. Concepts in dental public health. Philadelphia: Lippincott Williams \& Wilkins; 2005.

11. Ireland $R$, editor. Clinical textbook of dental hygiene and therapy. Oxford: Blackwell Munksgaard; 2006.

Two-Three Authors/Editors

12. Miles DA, Van Dis ML, Williamson GF. Radio-graphic imaging for the dental team. 4th ed. St. Louis: Saunders Elsevier; 2009.

13. Dionne RA, Phero JC, Becker DE, et al., editors. Management of pain and anxiety in the dental office. Philadelphia: WB Saunders; 2002.

More than Three Authors/Editors

14. Fauci AS, Braunwald E, Kasper DL, et al. editors. Harrison's principles of internal medicine. 17th ed. New York: McGraw Hill; 2008.

Organization as Author

15. Canadian Dental Hygienists Association. Dental hygiene: definition and scope. Ottawa: Canadian Dental Hygienists Association; 1995.

No Author/Editor

16. Scott's Canadian dental directory 2008. 9th ed. Toronto: Scott's Directories; 2007.

Chapter in a book

17. Alexander RG. Considerations in creating a beautiful smile. In: Romano $R$, editor. The art of the smile. London: Quintessence Publishing; 2005. p.187-210.

E-book

18. Irfan A. Protocols for predictable aesthetic dental restorations [Internet]. Oxford: Blackwell Munksgaard; 2006 [cited 2009 May 21]. Available from

Netlibrary: http://cclsw2.vcc.ca:2048/login?url=http://

www.netLibrary.com/urlapi.asp?action=

summary $\&=1 \&$ bookid $=181691$

Different Editions

19. Murtagh J. John Murtagh's General practice. 4th ed. Sydney: McGraw-Hill Australia Pvt Ltd; 2007.

An edition number is placed after the title of the work. This is not necessary for a first edition
Edited book

20. Brooks A, Mahoney P, Rowlands B, editors. ABC of tubes, drains, lines and frames. West Sussex: Blackwell Publishing Ltd; 2008.

Book in a series

21. Bennett GL, Horuk R. Iodination of chemokines for use in receptor binding analysis. In: Horuk $R$, editor. Chemokine receptors. New York (NY): Academic Press; 1997. p.134- 48. (Methods in enzymology; vol 288).

\subsection{Government Document}

Author(s). Title of report. Place of publication: Publisher; Date of publication - year month if applicable. Total number of pages if applicable eg. 24 p. Report No.: (if applicable)

22. Canada. Environmental Health Directorate. Radiation protection in dentistry: recommended safety procedures for the use of dental x-ray equipment. Safety Code 30. Ottawa: Ministry of Health; 2000.

\subsection{Elements of the citation for a thesis}

Printed Thesis

Author. Thesis title [type of thesis]. Place of pub- lication: Publisher; Year.

\section{Online Thesis}

Author. Thesis title [type of thesis on the inter- net]. Place of publication: Publisher; Year [cited date - year month day]. Available from: Name of database/web address

23. Kay JG. Intracellular cytokine trafficking and phagocytosis in macrophages [PhD thesis]. St Lucia, Qld: University of Queensland; 2007.

24. Pahl KM. Preventing anxiety and promoting social and emotional strength in early childhood: an investigation of aetiological risk factors [PhD thesis]. St Lucia, Qld: University of Queensland; 2009 [cited 2010 Mar 24]. Available from: University of Queensland Library E-Reserve 
Internet - web articles

Standard Format for website

Author Surname Initials (if available). Title of Website [Internet]. Place of publication: Publisher; Date of First Publication [Date of last update; cited date]. Available from: URL

Publication Information Online

- Publication information is often unavailable on websites and is not standardized like books or journals. Vancouver Style requires the "Place of Publication", the "Publisher" and the "Original Publication Date" as part of the citation. If these pieces of information are not given, use: [place unknown], [publisher unknown] or [date unknown].

- Add in square brackets the updated \& cited dates or add all the information into the cited year field and edit to suit

- If neither a date of publication nor a date of copyright can be found for a Web site, use the date of update/revision and/or the date cited

Note: JAIM requires additional pieces of information when citing resources: Short URLs (also referred to as 'tiny') are recommended.

\section{Examples}

Website with Author

25. Fehrenbach MJ. Dental hygiene education [Internet]. [Place unknown]: Fehrenbach and Associates; 2000 [updated 2009 May 2; cited 2009 Jun 15]. Available from: http://www.dhed.net/ Main.html

Website without Author

26. American Dental Hygienists' Association [Internet]. Chicago: American Dental Hygienists' Association; 2009 [cited 2009 May 30]. Available from: http://www.adha.org/

Part / Article within a Website

27. Medline Plus [Internet]. Bethesda (MD): U.S. National Library of Medicine; c2009. Dental health; 2009 May 06 [cited 2009 Jun 16]; [about 7 screens]. Available from: http://www.nlm.nih.gov/ medlineplus/dentalhealth.html

Blog

28. Skariah H. The tooth booth dental blog [Internet]. Mississauga (ON): Hans Skariah; 2004 - [cited 2009 Jun 20]. Available from: http://dentaldude.blogspot.com/

An Entry / Article within a Blog

29. Skariah $\mathrm{H}$. The tooth booth dental blog [Internet]. Mississauga (ON): Hans Skariah; 2004 - . Dental did you know: breastfeeding duration and non-nutritive sucking habits; 2009 May 18 [cited 2009 Jun 20]; [about 1 screen]. Available from: http://dentaldude.blogspot.com/2009/05/dental-did-you-knowbreastfeeding.html

Image on the Internet

30. McCourtie SD, World Bank. SDM-LK-179 [image on the Internet]. 2009 Apr 29 [cited 2009 Jun 14]. Available from: http:// www.flickr.com/photos/worldbank/3486672699/

\section{Podcasts}

31. Dirks, P. "Missing Link" fossil discovery in South Africa [podcast on the Internet]. Sydney: ABC Radio National; 2010 [updated 2010 Apr 9; cited 2010 Apr 14]. Available from: http:// www.abc.net.au/rn/breakfast/stories/2010/2868072.htm

\section{Other Resources}

Newspaper Articles

Author(s) - family name and initials. Article title. Newspaper title (edition of paper eg. Weekend edition). Date of publication year month (3 letter abbreviation) day: Sect. Location eg. A:12 or Business 5 ( 5 is the page number) column number is applicable eg. col. 1) (Sect = Section)

Like journals, newspapers are cited differently depending on how the article was accessed. Include a working "permanent link" to any

article accessed online.

32. Health Canada issues warning over fake toothbrushes. The Globe and Mail [Internet]. 2009 April 10 [cited 2009 Jun 23]. Available from: http://www.theglobeandmail.com/news/national/health-canada-issues-warning-over-fake-toothbrushes/ article973190/

33. Waldman D. Mouth is 'window on the rest of the body': oral health, dental hygiene is linked to more than teeth, gums.
The National Post [Internet]. 2009 Apr 14 [cited 2009 Jun 22]. Available from Canadian Newsstand: http://cclsw2.vcc. ca:2048/login?url=http://proquest.umi.com/pqdweb?did=16803 $06071 \&$ sid $=1 \&$ Fmt $=3 \&$ client $/ d=6965 \& R Q T=309 \&$ VName $=P Q D$

34 Fayerman P. Women must now wait to 40 for publicly paid amnio test. Vancouver Sun. 2009 Jun 9; Sect. A:5.

\section{Video Recordings}

35. Dental dam: still the best dry-field technique [DVD]. Provo (UT): Practical Clinical Courses; 2007.

36. Cuaron A, director; Abraham M, producer. Children of men [DVD]. Universal City (CA): Universal; 2006.

\section{Lecture notes}

Lecturer. Title of Lecture [unpublished lecture notes]. Course code: course name, Institution where delivered; lecture given date.

37. Blogs, J., 2008. Single nucleotide polymorphisms: lecture notes, University of Leicester 23rd February 2009. 


\section{Encyclopedia , Dictionary, or Similar Reference Book}

Entries in reference books are either signed or unsigned. The author will be listed at the start or end of the individual entry. An editor(s) will usually be listed at the front of the book but the editor is not included in the citation for reference works.

Unsigned

38. Mosby's dental dictionary. 2nd ed. St. Louis: Mosby Elsevier; 2008. Frenotomy; p. 273.

Signed (and Online)

39. Murchison DF. Dental emergencies. In: Merck Manual of Diagnosis and Therapy [Internet]. 18th ed. Whitehouse Station (NJ): Merck; 2009 [last modified 2009 Mar; cited 2009 Jun 23]. Available from: http://www.merck.com/mmpe/sec08/ch096/ ch096a.html?at=dental\&alt=sh

\section{Conferences}

Author(s) of paper - Family name and initials. Title of paper. In: Editor(s) Family name and initials, editor(s). Title of conference; Date of conference; Place of conference. Place of publication: Publisher's name; Year of publication. p. Page numbers.

A whole conference

40. Kimura J, Shibasaki H, editors. Recent advances in clinical neurophysiology. Proceedings of the 10th International Congress of EMG and Clinical Neurophysiology; 1995 Oct 15-19; Kyoto, Japan. Amsterdam: Elsevier; 1996.

A conference paper

41. Bengtsson S, Solheim BG. Enforcement of data protection, privacy and security in medical informatics. In: Lun KC, Degoulet $P$, Piemme TE, Reinhoff O, editors. MEDINFO 92. Proceedings of the 7th World Congress on Medical Informatics; 1992 Sep 6-10; Geneva, Switzerland. Amsterdam: North-Holland; 1992. p.15615.

\section{Personal Communications}

Personal communication (with the exception of email) should not be included in the Reference List, as they are unpublished and cannot be easily traced by the reader. Instead, acknowledge personal conversations and letters within the text in parentheses.

\section{Permission}

When citing any personal communication, you must have written permission from the cited person(s) to use that communication. Acknowledge the permission in a footnote or in a "Notes" section at the end of the text.

\section{Conversation}

42. "...in conversation with a fellow student from the Dental Hygiene program (Affleck, Ben. Conversation with: Matt Damon. 2008 Sep 07.)."

Personal Letter

43. "...this information was later confirmed in a letter (Hepburn, Katherine. Letter to: Spencer Tracy. 2005 Mar 03. 4 pages.)."

Email

Email correspondence is included in the Reference List as emails are easily traceable and dated.

44. Bloom, Orlando. Searching Medline for dental hygiene articles [Internet]. Message to: Johnny Depp. 2008 Nov 11 [cited
2009 Jun 22]. [3 paragraphs].

\section{Points to Remember}

1. Journal name abbreviation to be used - using Index Medicus guidelines

2. When you are writing your paper, always quote the science and not the scientist.

Although the names of researchers are quoted extensively in the behavioral sciences, they do not need to be quoted in clinical research. When you cite the work of other researchers, you need to compare your results with their results or say what they found. You should do this without using the authors' names in the text.

\section{Rather than writing}

Smith et al. found that the prevalence of diabetes in 1998 .... it is much more informative to write,

In a cross-sectional study con-ducted in 1998, the prevalence of diabetes was $8 \%$

3. When you are citing the literature in a paper, always use conservative phrases

Never say - It is widely believed that ...

when you have few recent references to back up the claim, or Much recent interest has centered around ... when few people have published on the topic in recent years

4. Similarly, phrases such as

It has long been known that ... or It is generally believed that ... are best avoided

5. All electronic references must give the same information as for a printed source but, because web content and addresses frequently change, web citations must include the retrieval date 


\section{Journal of Advances in Internal Medicine (JAIM) - Declaration Form}

Declaration of Authorship Responsibility, Financial Disclosure, Conflicts of interest, Copyright Transfer/Publication Agreement Each author must read the statements on Authorship Responsibility, Criteria, and Contributions; Reporting of Conflicts of Interest and Financial Disclosure; and Copyright Transfer/Publishing Agreement. Primary/Corresponding Author must sign this Declaration Form. Remaining Author/s should disclose related information via Authorship Statement Form. Instructions for authors are available online at http://www.aimjournal.org

Manuscript Title

[a] Authorship Responsibility, Criteria, and Contributions Author should meet all criteria below (A, B, C, and D) and should indicate general and specific contributions by reading criteria $A, B, C$, and $D$ and checking the appropriate boxes.

\section{$\square$ A. I certify that}

$\checkmark \quad$ The manuscript represents original and valid work and that neither this manuscript nor one with substantially similar content under my authorship has been published or is being considered for publication elsewhere, except as described in an attachment, and copies of closely related manuscripts are provided; and

$\checkmark$ If requested, I will provide the data or will cooperate fully in obtaining and providing the data on which the manuscript is based for examination by the editors or their assignees; and

$\checkmark \quad$ I agree to allow the corresponding author to serve as the primary correspondent with the editorial office, to review the edited typescript and proof, and to make decisions regarding release of information in the manuscript to the media, federal agencies, or both; or, if I am the only author, I will be the corresponding author and agree to serve in the roles described above.

$\square$ B. I have given final approval of the submitted manuscript.

$\square$ C. I have participated sufficiently in the work to take public responsibility for (check 1 of 2 below)

$\square$ part of the content

$\square$ the whole content

D. To qualify for authorship, you must check at least 1 box for each of the 3 categories of contributions listed below.

I have made substantial contributions to the intellectual content of the paper as described below.

1. (Check at least 1 of the 3 below)

$\square$ conception and design

$\square$ acquisition of data

$\square$ analysis and interpretation of data

2. (Check at least 1 of 2 below)

$\square$ drafting of the manuscript

$\square$ critical revision of the manuscript for Important intellectual content

3. (Check at least 1 below)

$\square$ statistical analysis

$\square$ obtaining funding

$\square$ administrative, technical, or material support

$\square$ supervision

$\square$ no additional contributions

$\square$ other (specify)

[b] Copyright Transfer / Publishing Agreement

I hereby transfer, assign, or otherwise convey all copyright ownership, including any and all rights incidental thereto, exclusively to the JAIM, in the event that such work is published by the JAIM. To reproduce the article in any form, I shall obtain prior permission from the Chief Editor.
Primary / Corresponding Author

Name

Telephone:

Email:

Affiliated Institute:

Country:

[c] Reporting of Conflicts of Interest and Financial Disclosure

$\square$ A. I certify that all funding, other financial support, and material support for this work are clearly identified in the manuscript.

$\checkmark$ B. I certify that all my competing interests, including specific financial interests and relationships and affiliations relevant to the subject matter or materials discussed in the manuscript (e.g.. employment/ affiliation, grants or funding, consultations, honoraria, stock ownership or options, expert testimony, royalties, or patents filed, received, or pending), are disclosed in the Acknowledgment section of the manuscript.

[d] Acknowledgement Statement

$\checkmark \quad$ Authors should obtain written permission from all individuals named in an Acknowledgment, since readers may infer their endorsement of data and conclusions. The corresponding author must sign on behalf of the whole team, the following statement:

$\checkmark \quad$ I certify that all persons who have made substantial contributions to the work reported in this manuscript (e.g. data collection, analysis, or writing or editing assistance) but who do not fulfill the authorship criteria (provided in the author guidelines) are name with their specific contributions in an Acknowledgment in the manuscript.

$\checkmark \quad$ I certify that all persons named in the Acknowledgment have provided me with written permission to be named.

$\checkmark \quad$ I certify that if an Acknowledgment section is not included, no other persons have made substantial contributions to this manuscript.

$\checkmark \quad$ I certify that I have obtained all written consent for publication of identifying material(s) from the authorities concerned, including ethics committee.

$\checkmark \quad$ In case if case review, or articles pertinent to involvement of human or animal subjects, I verify that I have obtained all written consent to carry out the works from the patients/ parents/ authorities concerned.

$\checkmark \quad$ I also understand that the decision of editor will be final regarding the manuscript and publication. I however, have the right to withdraw my manuscript when given a chance (e.g. after modification).

I will bear responsibility for any mistakes/irregularities in case any of the information provided above turns false.

Primary/Corresponding Author's Signature Date Signed (dd/mm/yyyy)

Please return all copies scanned as an e-mail attachment to editor@aimjournal.org along with the manuscripts and other required supplements. 